\title{
Pulmonary involvement in ankylosing spondylitis
}

\author{
NILS FELTELIUS, ${ }^{1}$ HANS HEDENSTRÖM, ${ }^{2}$ GUNNAR HILLERDAL, ${ }^{3}$ AND \\ ROGER HÄLLGREN ${ }^{1}$
}

From the Departments of ${ }^{1}$ Internal Medicine, ${ }^{2}$ Clinical Physiology, and ${ }^{3}$ Lung Medicine, University Hospital, Uppsala, Sweden

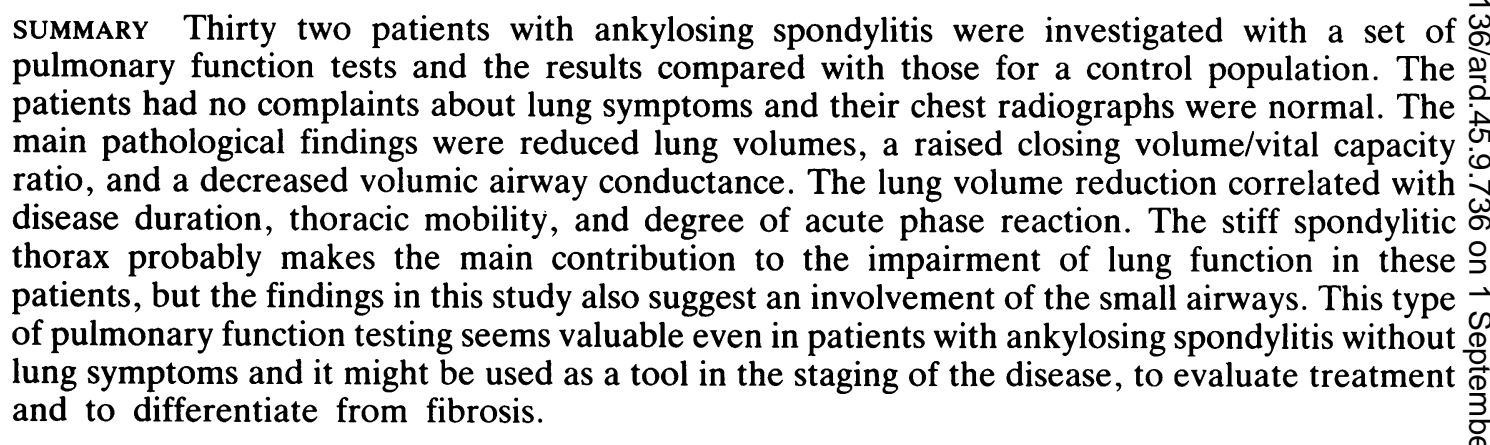

Key words: closing volume, lung mechanics, pulmonary function tests, small airways, thoraci $\overrightarrow{0}$ mobility.

Ankylosing spondylitis (AS) is a systemic rheumatic disease which apart from joint symptoms can affect several other organs. Involvement of the lungs measured as reduced lung volumes is a known manifestation of the disease. This has been suggested to be a consequence of reduced mobility of the thoracic cage. ${ }^{1}$ In recent years an association with the tissue antigen HLA-B27 and certain lung affections, mainly upper lobe fibrosis and secondary infections, has been proposed. ${ }^{2}$ This could indicate that immunological and inflammatory processes in the lung parenchyma might be as important as mechanical factors in the development of impaired lung function in AS. Earlier studies of pulmonary function in AS have dealt mostly with selected cases with advanced lung disease. ${ }^{3}$ In this study 32 patients consecutively recruited with definite AS, but lacking lung symptoms, all with the HLA-B27 antigen, were studied with several lung function tests and the results were correlated with disease duration, thoracic mobility, and degree of inflammatory activity.

Accepted for publication 17 March 1986.

Correspondence to Dr Nils Feltelius, Section of Rheumatology, Department of Internal Medicine, University Hospital, S-751 85 Uppsala, Sweden.

\section{Patients and methods}

Thirty two outpatients with definite AS according to American Rheumatism Association criteria (New York) were recruited consecutively for this study. No selection was made because of lung symptoms or $x$ ray findings. The clinical and laboratory features of five AS patients are shown in Table 1.

The following spirometric tests were performed: measurements of the total lung capacity (TLC), functional residual capacity (FRC), and residual volume (RV), together with airways resistance (Raw) and volumic airways conductance $(\mathrm{Gaw} / \mathrm{V})$ using a body plethysmograph; ventilatory capacity, including flow-volume curves for determination of vital capacity (VC), forced expiratory volume in one second $\left(\mathrm{FEV}_{1}\right), \mathrm{FEV}_{1}$ as percentage of VC $\left(\mathrm{FEV}_{1} /\right.$ VC), maximal voluntary ventilation at breathing rate of 40 breaths/min (MVV40), peak expiratory flow rate (PEF), and maximal expiratory flows at $75 \%, 50 \%$, and $25 \%$ of the forced vital capacity (MEF75, MEF50, and MEF25); single-breath nitrogen wash out test for measurement of the intrapulmonary gas distribution (phase III), closing volume (CV), and $\mathrm{CV}$ as percentage of $\mathrm{VC}(\mathrm{CV} / \mathrm{VC})$; transfer factor $\left(\mathrm{T}_{\mathrm{L}} \mathrm{CO}\right)$ or diffusing capacity for carbon monoxide (single-breath test) and measure- 
Table 1 Clinical and laboratory features of the patients with ankylosing spondylitis

\begin{tabular}{|c|c|c|c|}
\hline & Mean value & $S D$ & Range \\
\hline $\operatorname{Sex}\left(\sigma^{7} / Q\right)$ & $23 / 9$ & & \\
\hline Age & $37 \cdot 6$ & $10 \cdot 2$ & $18-57$ \\
\hline Disease duration (years) & $9 \cdot 7$ & $6 \cdot 6$ & $2-30$ \\
\hline $\begin{array}{l}\text { Smokers/non-smokers (three } \\
\text { ex-smokers) }\end{array}$ & $12 / 11$ & & \\
\hline $\begin{array}{l}\text { Thoracic mobility } \\
\text { (cm, fourth intercostal space) }\end{array}$ & $2 \cdot 86$ & 1.64 & $0 \cdot 5-7 \cdot 0$ \\
\hline $\operatorname{ESR}^{*}(\mathrm{~mm} / 1 \mathrm{st} \mathrm{h})$ & $25 \cdot 3$ & $19 \cdot 2$ & $3-70$ \\
\hline Haptoglobin $(\mathrm{g} / \mathrm{l})$ & 2.9 & 1.0 & $0 \cdot 8-5 \cdot 0$ \\
\hline Orosomucoid $(g / 1)$ & $1 \cdot 3$ & 0.4 & $0 \cdot 8-2 \cdot 5$ \\
\hline $\operatorname{Ig} A(g / 1)$ & 3.4 & $1 \cdot 2$ & $1.4-5 \cdot 6$ \\
\hline
\end{tabular}

*ESR=erythrocyte sedimentation rate.

ment of static compliance (Cst) and maximal elastic recoil pressure of the lungs $(\operatorname{Pel}(\max ))$. These pulmonary function tests have been described in detail elsewhere. ${ }^{45}$

Erythrocyte sedimentation rate (ESR) was read after one hour. Serum levels (reference ranges are given in parentheses) of haptoglobin $(0 \cdot 3-2 \cdot 0 \mathrm{~g} / \mathrm{l})$, orosomucoid $(0 \cdot 4-1 \cdot 2 \mathrm{~g} / \mathrm{l}$, and IgA $(0 \cdot 8-4 \cdot 0 \mathrm{~g} / \mathrm{l})$ were measured by nephelometry at the Department of Clinical Chemistry, University Hospital, Uppsala.

CALCULATIONS AND STATISTICS

The lung function values were expressed as residuals (observed value-predicted value) and as a percentage of predicted values using regression equations which take into account the effect of sex, age, body size, and smoking habits. ${ }^{45}$ In the statistical analysis the $t$ distribution was used to determine the significance level between the AS group and the normal reference group: 456 healthy subjects $(270$ men, 186 women) with normal chest radiographs. Half of the healthy subjects had never been smokers and half were smokers. The Pearson correlation coefficient was used to measure the correlation between pulmonary function variables and inflammatory activity variables. Discriminant analysis was used to detect optimal variables for discrimination between the AS group and normal subjects and between the AS group and patients with pulmonary fibrosis (38 patients with pleura plaques, 40 patients with silicosis on the basis of chest radiographs, and 33 stone crushers exposed to silicon dust but with normal chest radiographs). ${ }^{67}$

\section{Results}

LUNG FUNCTION AND LUNG VOLUMES Variables reflecting lung volumes and functions are
Table 2 Lung function in patients $(n=32)$ with ankylosing spondylitis

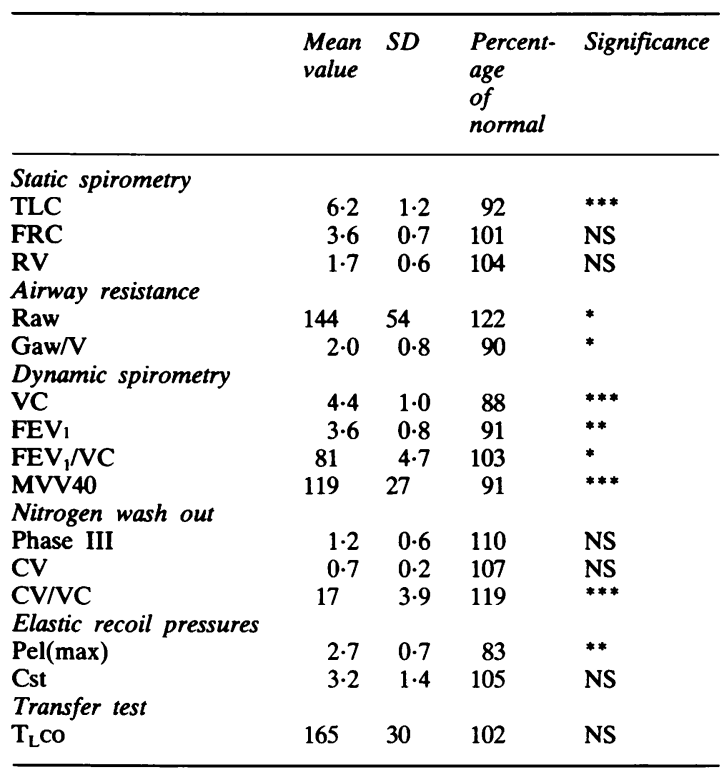

${ }^{*} \mathrm{p}<0.05,{ }^{* *} \mathrm{p}<0.01$, and ${ }^{* * *} \mathrm{p}<0.001$ compared with the reference subjects.

presented in Table 2. The AS patients had, compared with values for the healthy controls, significantly reduced lung volumes defined by total lung capacity (TLC) and vital capacity (VC). Forced expiratory volume $\left(\mathrm{FEV}_{1}\right)$ and maximal voluntary ventilation (MVV40) were also reduced. Functional residual capacity (FRC) and residual volume (RV) values were not different from those of the controls, suggesting a restrictive limitation of lung volume. The normal flow values (PEF, MEF75, MEF50, MEF25) and raised FEV/VC excluded an obstruction in the airways. No signs of increased stiffness in the lung parenchyma were observed as the maximal elastic recoil pressure $(\mathrm{Pel}(\max ))$ was decreased and the static compliance (Cst) was normal. No impairment of the diffusion capacity $\left(\mathrm{T}_{\mathrm{L}} \mathrm{CO}\right)$ was noted. Although the closing volume (CV) appeared normal, the significantly increased CV/VC ratio may suggest an oedema. or inflammatory reaction affecting the small airways. The presence of normal flow, together with a slight decrease of the volumic airway conductance $(\mathrm{Gaw} / \mathrm{V})$, is also compatible with an involvement of the small airways.

Discriminant analysis was used to construct a scored lung function profile that gave optimal sensitivity and specificity compared with values for healthy controls. The variables were expressed as 
738 Feltelius, Hedenström, Hillerdal, Hällgren

Table 3 Correlation coefficients between lung function tests and clinical and laboratory data

\begin{tabular}{|c|c|c|c|c|c|c|}
\hline $\begin{array}{l}\text { Lung } \\
\text { function } \\
\text { test }\end{array}$ & $\begin{array}{l}\text { Disease } \\
\text { duration } \\
\text { (years) }\end{array}$ & $\begin{array}{l}\text { Thoracic } \\
\text { expansion } \\
(\mathrm{cm})^{\dagger}\end{array}$ & $\begin{array}{l}E S R \\
(\mathrm{~mm} / 1 \mathrm{st} h)\end{array}$ & $\begin{array}{l}\text { Haptoglobin } \\
(g / l)\end{array}$ & $\begin{array}{l}\text { Orosomucoid } \\
(\mathrm{g} / \mathrm{l})\end{array}$ & $\begin{array}{l}\operatorname{Ig} A \\
(g / l)\end{array}$ \\
\hline TLC & $-0 \cdot 39^{* *}$ & $+0 \cdot 55^{* * *}$ & $-0 \cdot 40^{* *}$ & $-0 \cdot 43^{* *}$ & -0.28 & $-0 \cdot 31^{*}$ \\
\hline VC & $-0 \cdot 36^{*}$ & $+0.58^{* * *}$ & $-0.42^{* *}$ & $-0.43^{* *}$ & $-0.44^{* *}$ & $-0.29^{*}$ \\
\hline $\mathrm{FEV}_{1}$ & $-0 \cdot 43^{* *}$ & $+0 \cdot 48^{* *}$ & $-0 \cdot 39^{* *}$ & $-0 \cdot 31^{*}$ & $-0 \cdot 35^{*}$ & $-0 \cdot 23$ \\
\hline MVV40 & $-0 \cdot 22$ & $+0.44^{* *}$ & $-0.31^{*}$ & $-0 \cdot 24$ & $-0.29^{*}$ & \\
\hline
\end{tabular}

${ }^{*} \mathrm{p}<0.05,{ }^{* *} \mathrm{p}<0.01$, and ${ }^{* * *} \mathrm{p}<0.001$ compared with the reference subjects.

†Fourth intercostal space.

the number of SD from predicted values. The optimal discriminating profile was: $-0.07 \times \mathrm{VC}$ $+0.04 \times \mathrm{Cst}-0.02 \times \mathrm{Gaw} / \mathrm{V}-0.01 \times \mathrm{CV} / \mathrm{VC}$. The sensitivity obtained was $55 \%$ and the specificity against healthy controls $84 \%$ and against patients with lung fibrosis $75 \%$.
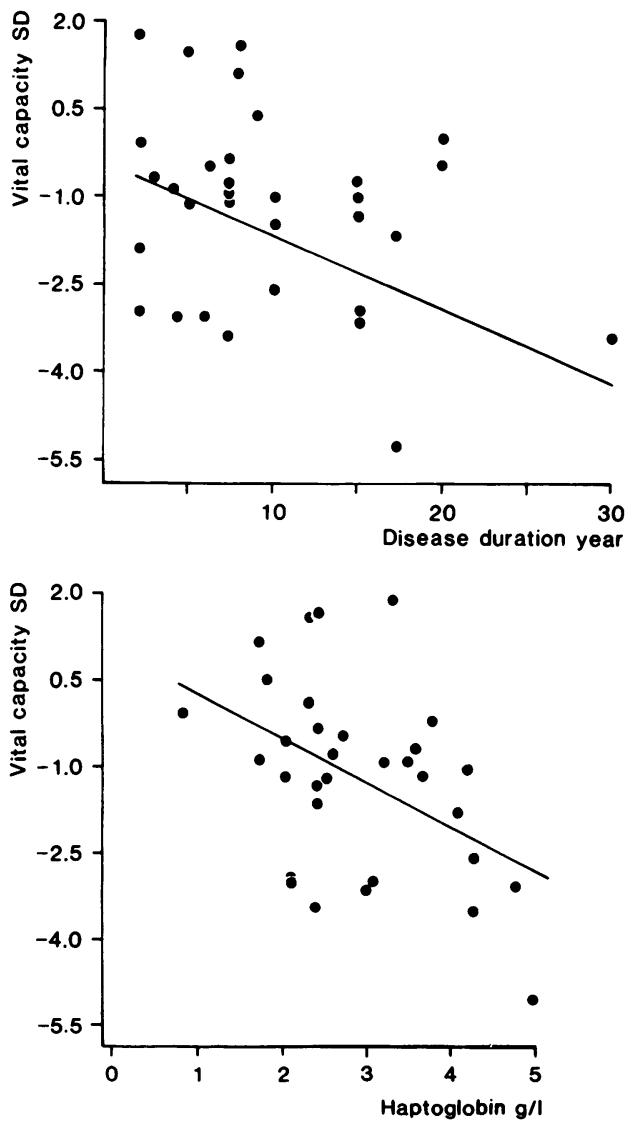

RELATION BETWEEN LUNG VOLUMES/ FUNCTIONS AND CLINICAL AND

LA B OR A T OR Y D A T A

The correlative studies are summarised in Table 3. and graphically illustrated in Fig. 1. The reduction $\omega_{\sigma}$ of the lung volumes estimated by different tech- 음
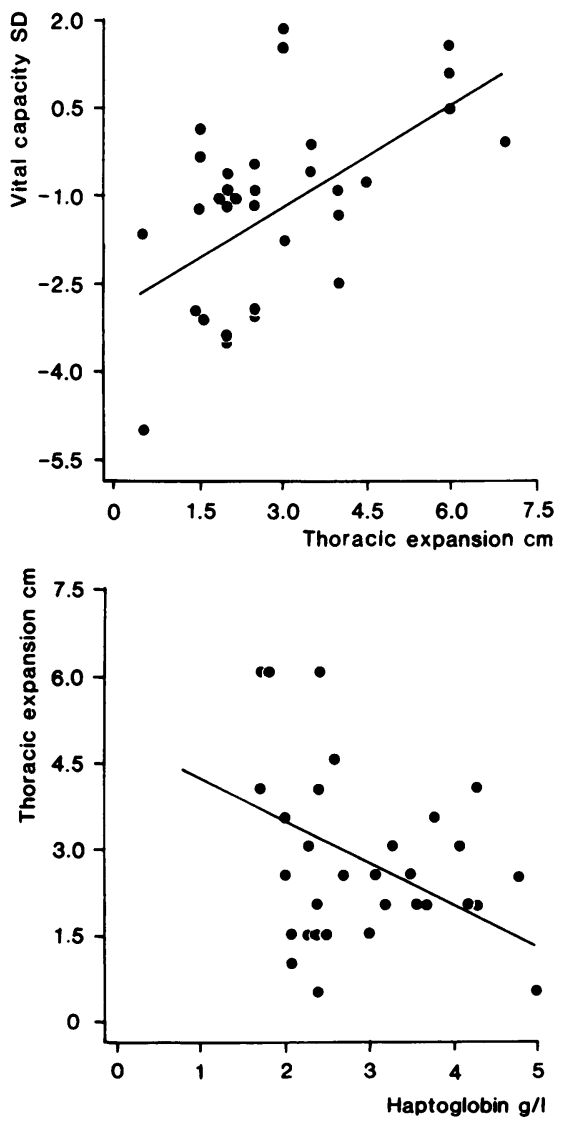

Fig. 1 Correlation between vital capacity, expressed as number of standard deviations (SD), and thoracic expansion, disease duration, and haptoglobin. Thoracic expansion $\mathrm{v}$ haptoglobin is also illustrated. 
niques was significantly related to the disease duration, thoracic mobility, and inflammatory activity defined by ESR, haptoglobin, orosomucoid, and IgA. The strongest correlations were observed between lung volumes and thoracic mobility (Table 3, Fig. 1). The thoracic mobility was also related to ESR $(r=-0.47, p<0.01)$, haptoglobin $(r=-0.42$, $\mathrm{p}<0.05)$, and orosomucoid $(\mathrm{r}=-0.56, \mathrm{p}<0.001)$. The minor abnormalities of the airway resistance did not correlate with these clinical and laboratory variables. Although the $\mathrm{CV}$ values did not differ from those of the controls we observed a negative relationship between $\mathrm{CV}$ and disease duration $(\mathrm{r}=-0.38, \mathrm{p}<0.05)$ and a positive relationship with thoracic mobility $(\mathrm{r}=0.38, \mathrm{p}<0 \cdot 05)$. The $\mathrm{CV} / \mathrm{VC}$ ratio tended to correlate with these clinical variables $(\mathrm{r}=-0.32, \mathrm{p}<0.05$ and $\mathrm{r}=0.23, \mathrm{p}=0.1$ respectively). $\mathrm{CV}$ and $\mathrm{CV} / \mathrm{VC}$ did not correlate with the inflammatory activity.

All patients except one had normal chest $x$ rays. The exception had bilateral upper lobe changes with infiltrates radiating from the hili.

\section{Discussion}

This study has shown that randomly selected patients with AS without symptoms of lung disease suffer from reduced lung volumes as defined by reduced vital capacity and reduced total lung capacity. Normal functional residual capacity and normal residual volume suggest a restrictive limitation of the lung volumes, further supported by the normal flow values. The reason for this lung function impairment could be an altered lung parenchyma with tendency to fibrosis or a reduced mobility of the thoracic cage due to inflammation or ankylosis of sternocostal and costovertebral joints and adjacent synchondroses. Since disease duration also was related to the reduction of lung volumes this suggests a process developing with time, finally resulting in a permanently reduced lung capacity. The observation that the reduced lung volumes were also related to inflammatory intensity of the disease may suggest an inflammatory involvement of the lung parenchyma. The acute phase reaction, however, was more strongly correlated with the thoracic mobility, which gives a more likely explanation of this relationship, namely that ongoing inflammatory processes in the thoracic joints give rise to pain and stiffness thus reducing the lung volumes. The concept that the inflammatory activity in the thoracic cage or in the lung parenchyma fluctuates in parallel with the activity of the rheumatic disease can only be decided by longitudinal studies.
The patients had no signs of increased lung stiffness and their diffusion capacity was normal. Involvement of the lung parenchyma cannot be fully excluded, however, considering the finding of a significantly increased $\mathrm{CV} / \mathrm{VC}$ ratio and a decreased volumic airway conductance. An increased phase III gives further support for this idea. ${ }^{89}$ The regression equations for lung function which have been used were originally developed in order to separate the smoking effect from other effects on lung function. In earlier studies it has been possible to do this, for instance in workers exposed to silica and asbestos. Thus the changes reported here cannot be explained by smoking habits and should be interpreted as an early interstitial reaction in the lung. Patients with established silicosis on the other hand are characterised by a tendency for a reduced CV/VC ratio. ${ }^{10}$

Previous studies on selected cases have reported upper lobe fibrosis in patients with AS and other diseases associated with HLA-B27. ${ }^{2}$ These patients have shown fibrotic changes, sometimes with cavitation and secondary aspergillomas. ${ }^{3}$ The upper lobe region is hypoventilated in the upright position in healthy humans, and this hypoventilation is likely to be more pronounced in a stiff, spondylitic thorax. ${ }^{11} 12$ Whether our findings of reduced lung volumes and a possible interstitial process can contribute to the development of upper lobe fibrosis can only be speculated on. Even though none of our patients complained about lung symptoms those with the most pronounced lung function impairment must be considered to be in a respiratory physiologically suboptimal state. From a practical, clinical point of view a multiple lung function analysis like that described here, defined by a score, could be a useful tool in the staging of the disease, to evaluate treatment and to differentiate from fibrosis.

\section{References}

1 Hart F D, Bogdanovitch A, Nichol W D. The thorax in ankylosing spondylitis. Ann Rheum Dis 1950; 9: 116-31.

2 Hillerdal G. Ankylosing spondylitis lung disease-an underdiagnosed entity? Eur J Respir Dis 1983; 64: 437-41.

3 Davies D. Ankylosing spondylitis and lung fibrosis. $Q \mathrm{~J} \mathrm{Med}$ 1972; 41: 395-417.

4 Hedenström H, Malmberg P, Agarwal K. Reference values for lung function tests in females. Regression equations with smoking variables. Clin Respir Phys 1985; 21: 551-7.

5 Hedenström H, Malmberg P, Fridriksson H V. Reference values for lung function tests in men. Regression equations with smoking variables. Ups $J$ Med $S c i$ (in press).

6 Norusis M K. Advanced statistics guide to SPSSx, SPSS Inc. New York: McGraw-Hill 1984.

7 Nie N H, ed. SPSSx users guide, SPSS Inc. New York; McGraw-Hill 1983.

8 Buist A S, Poss B B. Quantitative analysis of the alveolar plateau in the diagnosis of early airway obstruction. Am Rev Respir Dis 1973; 108: 1078-87. 
9 McCarthy D S, Spencer R, Greene R, Milic-Emili J. Measurement of 'closing volume' as a simple and sensitive test for early detection of small airway disease. Am J Med 1972; 52: 747-53.

10 Fridriksson $\mathrm{H} \mathrm{V}$. Early changes in respiratory function caused by occupational dust or tobacco smoking. Uppsala: University of Uppsala, 1980. (Thesis).
11 Stewart R M, Ridyard J B, Pearson J D. Regional lung function in ankylosing spondylitis. Thorax 1976; 31: 433-7.

12 Scobie B A. Disturbed oesophageal manometric responses in patients with ankylosing spondylitis and pulmonary aspergilloma. Aust Ann Med 1970; 19: 131-. 